\title{
Evaluation Research of Interior Design of Living Space Based on Grey System Theory
}

\author{
Ren Qiugang \\ Yibin University \\ wanghai1976@yeah.net
}

\begin{abstract}
The interior design of living space is important for improving the visual perception of people and the living quality, therefore the application of the grey system theory on evaluating the interior design is studied in depth. Firstly, the main contents of interior design for the living space are summarized. Secondly, the basic theory of grey system theory is studied. Thirdly, the evaluation index system of interior design of ling space is established according to the actual situation of the interior design of living space. Finally, a case study is carried out using 10 interior design plans as evaluation objectives, and the quality of every interior design is obtained based on the grey system theory.
\end{abstract}

Keywords: evaluation research; interior design; living space; grey system theory

\section{Introduction}

With the development of the economy and improvement of aesthetics of the general public, the requirement of people for the quality of life and living space are higher and higher. In recent years different orders of residences have been constructed, and the living conditions of people have been amended. The design level interior design of living space should be improved for suiting to the development of the architectural decoration industry. At present the house decoration has entered thousands of houses, and the decoration consumer of people has become more rational. The interior design of living space can give visual perception for people, and however there are still problems in the interior design of living space. For example, all kinds of plane or three-dimensional modeling are used in the procession of design, then all kinds of color division is added, this design model concludes visual pollution. Therefore it is necessary to evaluate the interior design of living space, and the existing problems can be found out, the individuation and personal customization interior design of living space can be obtained [1].

There are many evaluation methods for interior design of living space, such as analytic hierarchy process and fuzzy evaluation method. These evaluation methods are intuitive and convenient, but the existing evaluation methods have low efficiency, and human error cannot be eliminated [2]. The grey system theory is a technology system based on grey relational analysis with systems analysis, modeling, decision-making, controlling and evaluation. The grey relation is a basic conception of the grey system, which is an uncertain relation of the system factor on the subject behavior. The grey system theory has good advantage of measuring effect for the uncertain system with small sample and poor information. The grey system theory can be applied in evaluating interior design of living space, and then the disadvantages of traditional evaluation methods can be made up. 


\section{Main Contents of Interior Design for the Living Space}

With the development of the times, the requirement of people for the living environment is higher and higher, the living quality is concerned by people. The modern interior design of living space should be people oriented, and the designer should attentively designed photographic design works, the main contents of interior design conclude the follows aspects:

(1) Accessories

The accessories have become the integrated subjects that leaping over architectural ornament and fashion, livelihood and art. The developing direction of accessories is the space that can reflect confidence, demonstrate specific style and effect, and contain family and friends.

Accessories conclude the following classifications [3]:

(a) Furnishings: the furniture is the main furnishings of indoor environment, and it is also the main functional objects of indoor, then the modeling, color, texture and style of the furniture can affect the atmosphere of interior greatly. The furnishings should obey the whole requirement of interior design, and can offer the services presenting the atmosphere of the interior and brewing artistic conception.

(b) Fabric furnishings: the fabric is necessity in the life of people, and it is also the important content of indoor furnishings. The curtains, carpets, hangings and furniture masked fabric used as ornamentation largely except for the utility function.

(c) Arts and crafts furnishings: the art works used as furnishings can be divided into two classifications: One is the practical arts and crafts, and the other is appreciated arts and crafts. The features of the practical arts and crafts not only have the practical value but also have the decoration, such as ceramics. The characteristics of the appreciated arts and crafts are pure handicrafts, which can only has the appreciation function, such as bronzes.

(d) Calligraphy and painting furnishings: the calligraphy and painting is more artistic, and has elegant style, which can be used as the furnishings in the study and sitting room. The content of the calligraphy and painting can be chosen according to the different interior environment and decorative requirement.

(e) Ornamental plants: the ornamental plants can be divided into six classifications according to the shape, size, quality, color and smell, which are foliage plants (foliage plants), flowering plants (chrysanthemum), ornamental fruit plants (ardisiamamillata), stem and root plants (cactus), gesture types of plant (citrus Bergamot), and aromatic plants (fragrans).

(2) Lighting applications of interior design

The lighting is a major priority, the visual objects of the modern sitting room concludes from space to ancient now decorations.

(a) The sitting room is the center of daily living of people, and therefore the lightness of lighting should be complicated enough. Generally, the sitting room applies three levels of lighting. The direct lighting can be used on the top of the sitting room, for different lamps and lanterns, and different lampshade can show different light quality. The indirect lighting can give the soft light, which can foil the sweet atmosphere. The auxiliary lighting can strengthen the illumination of any region, and make the space have sense of hierarchy, and can offer the soft atmosphere of interior space.

(b) The bedroom is the rest space of people, and the local lighting can be fixed on the bedside and toilet table, which can be benefit for the reading and dressing, the strip lamp with low-light level can be fixed vertically the two sides of dresser, the rendering properties of lighting are good, and the natural skin color can be shown. The wall fitting with equal beams is fixed on two sides of bedside, which can be regulated and switched independently to meet the requirement of people. 
(c) The study is the private space after the private space, people can think independently, write, and search information by computer, and make a plan in the study, therefore, the atmosphere of the study should be quiet sedate, therefore the lighting should be applied in this direction. The indirect lighting is necessary for the study, which can avoid the visual glare harm for the direct radiation of lighting.

(d) The dining room is the place to eat, therefore the lighting give people the feeling with a little warm, and make people feel the atmosphere of having a dinner. The chandelier can be used in the dinning room, the light beam of the chandelier can radiate directly on the dining-table, the brightness is enough. In addition the special lamps can add the atmosphere of dinning room,

(e) The toilet needs the bright and soft light, because the illuminator in the toilet can be switched frequently, it is good to use filament lamp as the illuminant.

(3) The color application of interior space

The color is an important means to express the beauty of the interior modeling, if the color is applied properly, the function of enriching the modeling and highlighting effect, and the different atmosphere and natures of interior can be expressed sufficiently. The interior color mainly manifests in the application of the tone, color lump and colored light. The color can cause visual reaction of people easier than shape, it can affect the emotion and psychology of people directly, the color can change the environment and atmosphere of interior, the proper application of color can create the rich beauty [4].

(4) Simple design

The complicated decoration and too rich color can make the sight line of people be full of contents, which can not be suit for the crowd with high strength work in modern society. These people can calm down in the simple living environment. The simple design can give people the sense of family, and the decoration and arrangement of environment are not too chaotic. The main applications conclude material performance, the individuation embodiment and simple furnishings.

\section{Basic Theory of Grey System Theory}

The basis of the grey system theory is the grey relational space, the main basis concludes the existing information and original series, and the grey procession and grey generation are used to process the original series and analyze the data, the model system mainly based on grey model (GM) can be constructed, which can predict the developing trend of system.

(1) GM $(1, N)$ model

The mathematical model in grey theory generally named as GM model, where G denotes the grey, and $\mathrm{M}$ denotes the model. The meaning of $\operatorname{GM}(1, \mathrm{~N})$ is the mathematical model with 1 order and $\mathrm{N}$ variable quantities [5].

The basic theory and feature of GM model concludes the following aspects:

(a) The normal system analysis theory can only construct the difference model, and cannot construct the differential model, while the grey theory can construct the differential equation model. The difference model is recursive model, can only develop according to the stage analysis, and only be applied in short run analysis, and describe the obvious changes of system. Essentially the derivative signals can be obtained, therefore there are no solutions. The main basis of constructing differential equation model based on the grey system theory conclude relational degree convergence, generation number and the grey derivative and other technologies.

(b) The data series of the grey system generally have not good regularity, and often are in the status of random. Based on the basic idea of the grey system theory can consider all random variables as the grey quantities in a certain range. The data analysis method is used for the grey quantities, which names as the data generation method, and the original data without the regularity can be transferred into series with regularity, the corresponding 
analysis is carried out. The researching objective of the grey theory has the characteristics of fuzzy, and the corresponding data has not any regularity, but the system has the orderliness, and also has the whole function. Therefore, the data without the regularity hides regularity, the procession of generating the grey number refers to find out the potential regularity from the original data [6].

(c) The grey theory can process the modeling problems of high order system based on several GM $(1, \mathrm{~N})$.

(d) The grey theory can establish the GM $(1,1)$ model based the difference between the calculation of model and real value, which is the main method for improving the precision of the model. The GM $(1,1)$ with residuals generally only focuses on the real regularity and the correction of the new data, therefore the GM $(1,1)$ with residuals is also inconsistent with the main model in time, therefore the grey predicting model often belongs to the differential model

(e) During the procession of modeling of the grey theory, three inspection methods are applied, which conclude the inspecting the value of the residuals, back inspection error and relational degree.

(2) Relational degree

The relational degree belongs to a technology method, which can be applied in analyzing the relational degree of different factors in the system, or the quantitative way is used to analyze the relational degree of different factors. The relational degree analysis belongs to a mathematical method, the main idea is to replace the approximate convergence as the infinite convergence, and replace the limited series as the system problem in infinite space, and replace the discrete data as the continue concept.

The parameter series is defined by $X_{0}$, and the compared series is defined by $X_{i}$, $i=1,2, \cdots, N$, and the corresponding expressions are listed as follows [7]:

$$
\begin{aligned}
& X_{0}=\left\{X_{0}(1), X_{0}(2), \cdots, X_{0}(N)\right\} \\
& X_{i}=\left\{X_{i}(1), X_{i}(2), \cdots, X_{i}(N)\right\}
\end{aligned}
$$

The relational coefficient between $X_{0}$ and $X_{i}$ in $l$ point can be expressed as follows:

$$
\xi_{i}(k)=\frac{\frac{\min }{i} \frac{\min }{l}\left|X_{0}(l)-X_{i}(l)\right|+\lambda \frac{\max }{i} \frac{\max }{l}\left|X_{0}(l)-X_{i}(l)\right|}{\left|X_{0}(l)-X_{i}(l)\right|+\lambda \frac{\max }{i} \frac{\max }{l}\left|X_{0}(l)-X_{i}(l)\right|}
$$

where, $\quad\left|X_{0}(l)-X_{i}(l)\right|=\Delta_{i}(l) \quad$ denotes the absolute difference, $\frac{\min }{i} \frac{\min }{l}\left|X_{0}(l)-X_{i}(l)\right|$

$\frac{\min }{l}\left|X_{0}(l)-X_{i}(l)\right|$

denotes the minimum difference of two levels, $\frac{\min }{i}\left(\frac{\min }{l}\left|X_{0}(l)-X_{i}(l)\right|\right)$

denotes the minimum of the second level. $\frac{\max }{i} \frac{\max }{l}\left|X_{0}(l)-X_{i}(l)\right|$ the resolution ratio, $\lambda \in[0,1]$ 。

The relational degree ${ }^{r_{i}}$ between the whole curve $X_{i}$ and reference curve $X_{0}$ can be calculated by the following expression [8]: 


$$
r_{i}=\frac{1}{n} \sum_{i=1}^{n} \xi_{i}(l)
$$

(3) Generation number

The grey theory can generate the equation by additive means, which is defined by AGO, the regressive means or reverse additive means can be defined by IAGO.

The original data series is defined by $X^{(0)}$, the generating series through $k$ times additive operations can be defined by $X^{(k)}$, the corresponding expressions are listed as follows:

$$
\begin{aligned}
& X^{(0)}=\left\{X^{(0)}(1), X^{(0)}(2), \cdots, X^{(0)}(N)\right\} \\
& X^{(r)}=\left\{X^{(r)}(1), X^{(r)}(2), \cdots, X^{(r)}(N)\right\}
\end{aligned}
$$

The mathematical model of AGO algorithm can be expressed as follows:

$$
X^{(r)}(l)=\left[X^{(r-1)}(1)+X^{(r-1)}(2)+\cdots+X^{(r-1)}(l-1)\right]+X^{(r-1)}(l)
$$

The series of $X^{(r)}$ after $i$ times regressive operations can be defined by $a^{(i)}\left(X^{(r)}(l)\right)$, and the expression of IAGO algorithm can be listed as follows:

$$
a^{(i)}\left(X^{(r)}(l)=a^{(i-1)}\left(X^{(r)}(l)\right)-a^{(r-1)}\left(X^{(r)}(k-1)\right), \quad i=1,2, \cdots, r\right.
$$

\section{Evaluation Index System of Interior Design of Ling Space}

\begin{tabular}{|c|c|}
\hline First grade index & Second grade index \\
\hline \multirow{5}{*}{ Accessories (A1) } & Furnishings (A11) \\
\hline & Fabric furnishings (A12) \\
\hline & Arts and crafts furnishings (A13) \\
\hline & Calligraphy and painting furnishings (A14) \\
\hline & Ornamental plants (A15) \\
\hline \multirow{5}{*}{$\begin{array}{l}\text { Lighting applications of } \\
\text { interior design (A2) }\end{array}$} & Lighting applications of sitting room (A21) \\
\hline & Lighting applications of bedroom (A22) \\
\hline & Lighting applications of study (A23) \\
\hline & Lighting applications of dining room (A24) \\
\hline & Lighting applications of toilet (A25) \\
\hline \multirow{3}{*}{$\begin{array}{l}\text { Color application of } \\
\text { interior space (A3) }\end{array}$} & Application of the tone (A31) \\
\hline & Application of color lump (A32) \\
\hline & Application of colored light (A33) \\
\hline \multirow{3}{*}{$\begin{array}{l}\text { Simple design of living } \\
\text { space (A4) }\end{array}$} & Material performance (A41) \\
\hline & Individuation embodiment (A42) \\
\hline & Simple furnishings (A43) \\
\hline
\end{tabular}

Based on the principles of scientificalness, totality, whole optimization, comparability and feasibility, the evaluation index system of interior design of living space is established, which is shown in Table 1.

Table 1. Evaluation Index System of Interior Design of Living Space 


\section{Results and Discussion}

Ten design plans of living space are chosen to carried out the analysis, the data comes from empirical study, the weight of every index can be obtained based on the grey system theory, and the corresponding calculating results are shown in Table 2

Table 2 Weight of Every Index

\begin{tabular}{|c|c|c|c|}
\hline First grade index & ht weig & $\begin{array}{l}\text { Second grade } \\
\text { index }\end{array}$ & $\begin{array}{r}\text { Weig } \\
\text { ht }\end{array}$ \\
\hline \multirow{5}{*}{ A1 } & \multirow{5}{*}{0.24} & A11 & 0.15 \\
\hline & & A12 & 0.22 \\
\hline & & A13 & 0.23 \\
\hline & & A14 & 0.28 \\
\hline & & A15 & 0.12 \\
\hline \multirow{5}{*}{ A2 } & \multirow{5}{*}{0.29} & A21 & 0.15 \\
\hline & & A22 & 0.18 \\
\hline & & A23 & 0.22 \\
\hline & & A24 & 0.25 \\
\hline & & A25 & 0.20 \\
\hline \multirow{3}{*}{ A3 } & \multirow{3}{*}{0.37} & A31 & 0.25 \\
\hline & & A32 & 0.40 \\
\hline & & A33 & 0.35 \\
\hline \multirow{3}{*}{ A4 } & \multirow{3}{*}{0.10} & A41 & 0.28 \\
\hline & & A42 & 0.37 \\
\hline & & A43 & 0.35 \\
\hline
\end{tabular}

Then the evaluation results of every interior design of the living space can be calculated based on the relational coefficient matrix and weight, and the relational degree of every interior design is listed in Table 3.

Table 3. Evaluation Results of 10 Interior Design of Living Space

\begin{tabular}{|c|c|c|}
\hline $\begin{array}{c}\text { Order number of interior } \\
\text { design }\end{array}$ & $\begin{array}{c}\text { Relational } \\
\text { degree }\end{array}$ & Ranking \\
\hline 1 & 0.27 & 9 \\
\hline 2 & 0.45 & 5 \\
\hline 3 & 0.15 & 10 \\
\hline 4 & 0.54 & 2 \\
\hline 5 & 0.51 & 4 \\
\hline 6 & 0.63 & 1 \\
\hline 7 & 0.52 & 3 \\
\hline 8 & 0.35 & 7 \\
\hline 9 & 0.44 & 6 \\
\hline 10 & 0.28 & 8 \\
\hline
\end{tabular}


As seen from the Table 3, the sixth interior design of living space is best, and the third interior design of the living space is poorest, the good and bad of every interior design of living space can be obtained based on the final results.

\section{Conclusions}

The grey system theory is introduced into the evaluation of interior design of living space, and the evaluation plan and methods are designed, and the original data can be used positively. And the good evaluation results can be obtained according to the case study, and this method is easy to use, which can be applied in the evaluation of interior design of living space widely.

\section{References}

[1] M. Fesanghary, S. Asadi and Z. W. Geem, "Design of low-emission and energy-efficient residential buildings using a multi-objective optimization algorithm", Building and Environment, vol. 49, no. 3, (2012), pp. 245-250.

[2] N. Xu, L. Tian and F. Dai, "Inspiration of New Chinese-Style Interior Design from Ming-Style Furniture", Applied Mechanics and Materials, vol. 361-363, no. 1, (2013), pp. 484-487.

[3] R. A. Opoku and A. G. Abdul-Muhmin, "Housing preferences and attribute importance among lowincome consumers in Saudi Arabia", Habitat International, vol. 34, no. 2, pp. 219-227.

[4] B. Xu and H. Y. Li, "Application Study on Biological Materials in Interior Design", Advanced Materials Research, vol. 460, no. 1, pp. 321-324.

[5] E. Kayacan, B. Ulutas and O. Kaynak, "Grey system theory-based models in time series prediction", Expert Systems with Applications, vol. 37, no. 2, (2010), pp. 1784-1789.

[6] M.-S. Yin, "Fifteen years of grey system theory research: A historical review and bibliometric analysis", Expert Systems with Applications, vol. 40, no. 7, (2013), pp. 2767-2775.

[7] C. Bai and J. Sarkis, "Integrating sustainability into supplier selection with grey system and rough set methodologies", International Journal of Production Economics, vol. 124, no. 3, (2010), pp. 252-264.

[8] C. Zhang and H. Zhang, "Analysis of aerobic granular sludge formation based on grey system theory", Journal of Environmental Science, vol. 25, no. 4, (2013), pp. 710-716. 
International Journal of Hybrid Information Technology

Vol.9, No.1 (2016) 